\section{Commentary: How aggressive should we be in replacing the aortic root during type A dissection?}

\section{Francois Dagenais, MD}

Bojko and colleagues ${ }^{1}$ report a single-institution retrospective study comparing root replacement or repair strategies in 716 patients without Marfan syndrome operated on for acute type A dissection between 2002 and 2017. Similar clinical outcomes were noted with both approaches, although a greater rate of recurrent, moderate or greater aortic regurgitation (AI) and sinus of Valsalva (SOV) dilatation occurred in the root repair group.

Overall, a majority of patients, 585 of $716(81.7 \%)$, underwent a root repair. The decision to perform a root replacement was influenced by a younger age, the presence of a bicuspid aortic valve, the severity of the preoperative $\mathrm{AI}$, and a larger SOV size (root replacement: $47 \mathrm{~mm}$ vs root repair: $38 \mathrm{~mm}$ ). Perioperative mortality was greater in the root-replacement group $(18.3 \%$ vs $8.4 \% ; P=.03$ after matching), possibly linked to the added technical complexity of a root-replacement procedure, as supported by the increased cardiopulmonary bypass time in the replacement group. At midterm, authors reported similar survival and stroke rates in both groups. As expected, presence of moderate or greater AI at midterm was significantly greater in the repair group and related to the severity of the preoperative AI but not to the preoperative SOV diameter. SOV diameter $\geq 45 \mathrm{~mm}$ at midterm was increased in the repair group $(11.1 \%$ vs $3.1 \%)$. Noteworthy, 50 of $585(8.5 \%)$ of patients presented a

\footnotetext{
From the Quebec Heart and Lung Institute, Department of Cardiovascular Surgery, Laval University, Sainte-Foy, Quebec, Canada.

Disclosures: The author reported no conflicts of interest.

The Journal policy requires editors and reviewers to disclose conflicts of interest and to decline handling or reviewing manuscripts for which they may have a conflict of interest. The editors and reviewers of this article have no conflicts of interest.

Received for publication April 16, 2020; accepted for publication April 17, 2020; available ahead of print May 1, 2020.

Address for reprints: Francois Dagenais, MD, Department of Cardiovascular Surgery, Institut Universitaire de Cardiologie et Pneumologie de Québec, 2725 Chemin Sainte-Foy, Sainte-Foy, Quebec, Canada, G1V 4G5 (E-mail: francois.dagenais@ chg.ulaval.ca).

J Thorac Cardiovasc Surg 2022;163:911-2

$0022-5223 / \$ 36.00$

Copyright (c) 2020 by The American Association for Thoracic Surgery

https://doi.org/10.1016/j.jtcvs.2020.04.062
}

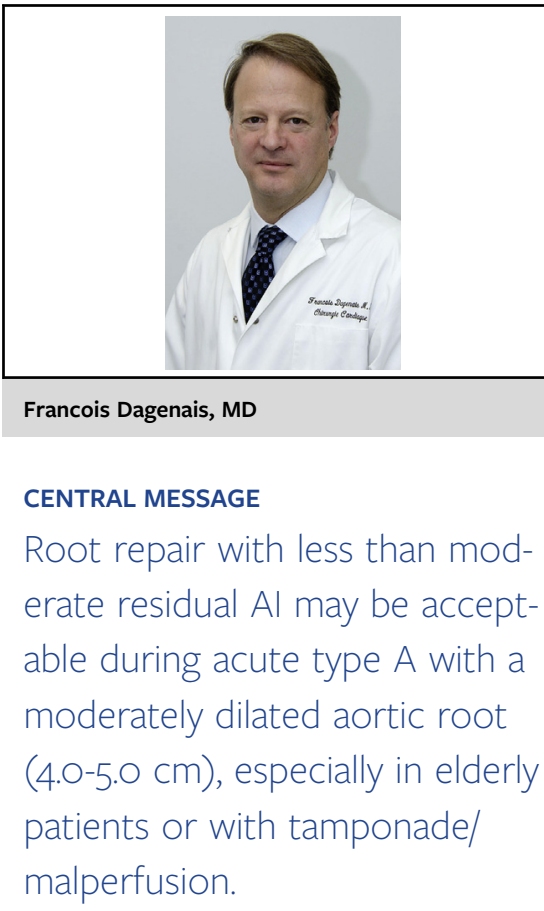

SOV diameter $\geq 45 \mathrm{~mm}$ preoperatively. Furthermore, only 19 of 69 patients with an SOV diameter $\geq 45 \mathrm{~mm}$ showed moderate or greater $\mathrm{AI}$ at follow-up. Interestingly, at a mean clinical follow-up of $4.9 \pm 4.1$ years, rate of reoperation was low $(17 / 716 ; 2.4 \%)$ and comparable for both groups. However, indication for reoperation differed among groups, with abscess/endocarditis as the main indication in the replacement group and progression of AI or root dilatation in the root repair group.

Although the authors have to be commended on tackling a difficult clinical problem, study limitations should be outlined. Measurements of SOV were based solely on transthoracic echocardiography reports without imaging review or computed tomography confirmation. In addition, only $57 \%$ of patients had transthoracic echocardiography data $>1$ year and $26.8 \%>5$ years.

Considering the study limitations, the present manuscript may shed some light on the management of the aortic root during acute type $\mathrm{A}$ dissection. In the presence of a moderately dilated aortic root $(4.0-5.0 \mathrm{~cm})$, root repair with less than moderate residual AI may be an acceptable procedure at midterm, especially in an elderly/comorbid population or patients with severe hemodynamic compromise/malperfusion. Opting for a root replacement in such a high-risk cohort of patients may lead to an increased perioperative mortality with minimal to no 
midterm benefit. Future studies are required to better delineate the ideal root procedure strategy in a low- to moderaterisk population with a moderately dilated aortic root.

\section{Reference}

1. Bojko MM, Assi R, Bavaria JE, Suhail M, Habertheuer A, Hu RW, et al. Midterm outcomes and durability of sinus segment preservation compared with root replacement for acute type A aortic dissection. J Thorac Cardiovasc Surg. 2022;163:900-10.e2.
See Article page 900.

\section{Commentary: Surgery of acute type A aortic dissection: Are we appropriately managing the aortic root?}

\author{
Jean Bachet, MD, FEBCTS
}

In their article appearing in the present issue of the Journal, Bojko and colleagues ${ }^{1}$ report on the immediate and late results of 2 techniques of management of the aortic root in a very large cohort of patients operated on emergently for acute type A aortic dissection. Through a sophisticated statistical analysis, the authors properly discuss the various aspects and differences between the 2 techniques (aortic root repair or replacement) and clearly conclude that "Patients undergoing root repair for ATAAD have similar clinical outcomes compared with patients undergoing root replacement. However, there may be a higher risk of recurrent aortic insufficiency (AI) and sinus of Valsalva (SOV) dilation after root repair compared to root replacement."

In this matter, this study is contributory. However, it raises an important question that has been rather ignored since the beginning of surgery of acute dissection: Do we appropriately deal with the aortic root?

For several decades, the difficulty of this surgery forced surgical teams to use the simplest and fastest possible

From the Senior Consultant Surgeon (Retired), Suresnes, France.

Disclosures: The author reported no conflicts of interest.

The Journal policy requires editors and reviewers to disclose conflicts of interest and to decline handling or reviewing manuscripts for which they may have a conflict of interest. The editors and reviewers of this article have no conflicts of interest.

Received for publication April 23, 2020; accepted for publication April 23, 2020; available ahead of print May 4, 2020.

Address for reprints: Jean Bachet, MD, FEBCTS, Association pour le Développement des Techniques de Dépistage et de Traitement des Maladies Cardio-vasculaires, 1, place Marcel Legras, 92150 Suresnes, France (E-mail: jean. bachet@yahoo.fr).

J Thorac Cardiovasc Surg 2022;163:912-3

$0022-5223 / \$ 36.00$

Copyright $($ C 2020 by The American Association for Thoracic Surgery

https://doi.org/10.1016/j.jtcvs.2020.04.061
Check for updates

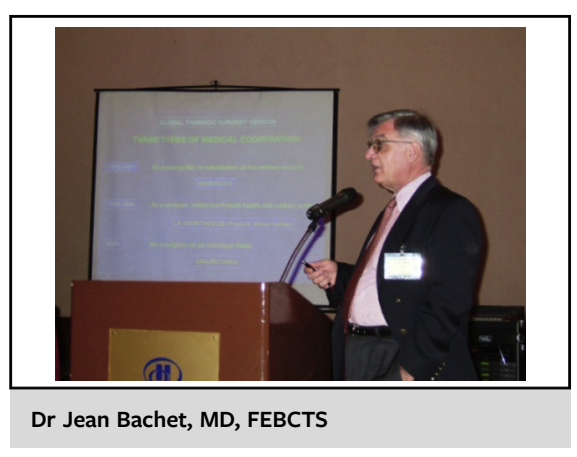

CENTRAL MESSAGE

Most techniques concerning the aortic root consist in repairing it or performing a Bentall procedure. Could the systematic use of valve-sparing procedures result in more stable long-term outcomes?

techniques. And, indeed, the statement: “ ...acute type A dissection is an inherently lethal condition. Our first job is to produce a live patient" made by John Elefteriades 2 decades $\mathrm{ago}^{2}$ was extremely relevant. Yet, with the progresses made during the last decades (implantation of cardiopulmonary bypass before opening the chest, arterial cannulation through a supra-aortic artery, selective antegrade cerebral perfusion, moderate core hypothermia, myocardial protection, etc) this imperative, even though it is still quite important, is associated presently with the one of ensuring the patient's long-term future.

It is indeed rather disappointing to observe that in the reported experience, whatever the technique used, and the immediate results obtained postoperatively, the mortality rate in both groups was more than $30 \%$ at 5 years. Similarly, it is somewhat worrisome to observe that $2.5 \%$ of the patients required a late reoperation on the root. This is not surprising in the "repair" group, since it is logical (and observed in most reported experiences) that, with time, some repaired dissected roots could dilate and aortic valves start regurgitating. It may seem more surprising in 